\title{
DEVELOPING A NEW SOFTWARE TOOL FOR RESEARCH OF INTERSTATE POWER GRIDS EXPANSION
}

\author{
Ivan L. Trofimov ${ }^{1}$, Leonid N. Trofimov ${ }^{1, *}$ \\ ${ }^{1}$ Melentiev Energy Systems Institute of Siberian Branch of the Russian Academy of Sciences, Electric Power Systems Department, \\ 664033, 130, Lermontova Str., Irkutsk, Russia
}

\begin{abstract}
The aim of our research is to develop a new software tool - the Computing and Geo-information System for study of prospective interstate power grids expansion. The new software tool developed by the authors consists of several functional parts (software modules): graphic module for visual analysis of processed data, geo-information and cartographic module, module for working with the integrated ORIRES model (model for optimization of power systems expansion and their operating modes). In this paper, we consider features and technical description of the new software tool. The obtained results of the integrated ORIRES model in tabular, graphic and cartographic forms are presented.
\end{abstract}

\section{Introduction}

The formation of interstate power grids (ISPG) in various regions of the world is due to positive effects to be obtained: increased reliability of electric power systems and uninterrupted power supply, wide involvement of renewable energy sources, and significant economic benefits. ISPG requires justification of its technical and economic efficiency, forecast of further expansion, coordination of economic and political interests, compliance with the technical standards of the participating countries, and consideration of many other aspects [1-3]. These researches require a lot of preliminary work to collect and analyze a huge amount of energy and power data, technical and economic calculations, and significant intellectual and information resources. A mathematical model for optimization of power systems expansion and their operating modes (named ORIRES) has been developed and applied at the Energy Systems Institute for the analysis and forecasting of the prospective ISPG expansion [4-6]. Without new information technologies that reflect the specifics of this subject area, research on the model takes a lot of time and human resources. To increase efficiency of research and to analyze multidimensional results, a convenient software interface is required.

To solve these problems, the authors have developed the Computing and Geoinformation System (the CGIS), which consists of a graphical (geoinformation) part and a computing part with an integrated ORIRES model and with the ability of its multiple configurations [7-9].

\section{Functional modules of the CGIS}

\footnotetext{
* Corresponding author: $\mathrm{t}$ john88@isem.irk.ru
}

The CGIS, developed by the authors consists of several functional parts (software modules): graphic module for visual analysis of processed data, geo-information and cartographic module, module for working with the ORIRES model.

Using a special CGIS interface, the user can configure the parameters and nodes of the model, launch the optimizer, and get the optimal solution for the objective function. All data used in the CGIS are stored and processed in the own object-oriented database. Each module is intended to solve specific problems. They can be divided into three groups:

1. Optimization and computing problems:

a. assessment of the effectiveness of interstate electric ties;

b. assessment of the integration level and efficiency of interstate power grids;

c. optimization of electricity generation capacities and operating modes for energy power systems (EPS);

d. study of EPS and ISPG expansion in different regions.

2. Information-analytical problems:

a. storage of energy and power data, collected from various sources in a uniform structure;

b. data analysis over various periods to reveal trends of electric power industry development;

c. graphic and cartographic data representation atlas geo-information mapping [10].

3. The research results coverage in Internet to attract of international scientific community. Based on the CGIS, the authors have developed an external energy informational and analytical web-service. 


\section{Object-oriented data base}

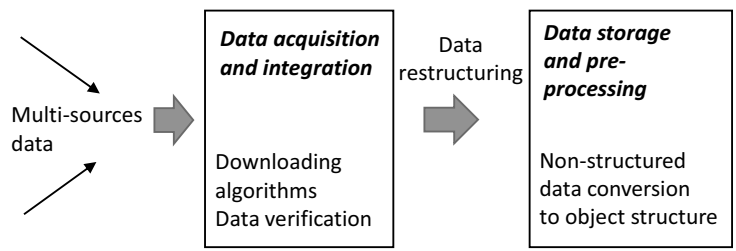

Figure 1 shows the data loading and analysis processes in the CGIS.

\begin{tabular}{|l|l|l|}
$\begin{array}{l}\text { Data } \\
\text { computing }\end{array}$ & $\begin{array}{l}\text { Data } \\
\text { processing }\end{array}$ & $\begin{array}{l}\text { Data analysis } \\
\text { and } \\
\text { presentation } \\
\text { Computing }\end{array}$ \\
algorithms, \\
$\begin{array}{l}\text { Math Model } \\
\text { solving }\end{array}$ & & $\begin{array}{l}\text { Data analysis } \\
\text { and } \\
\text { presentation } \\
\text { algorithms }\end{array}$ \\
\hline
\end{tabular}

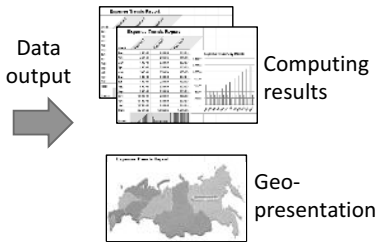

Fig. 1. The data loading and analysis processes in the CGIS.

All information received from various sources is structured and stored as unique database objects. Then the user can configure scenarios of ISPG and run the model. The resulting output is a set of tables with optimal parameters for all ISPG nodes. The obtained data are analysed in tabular, graphical, and cartographic forms in the CGIS, and exported to Excel.

The object-oriented database (OODB) developed by the authors is used for storing and processing data in the
CGIS. The essence of data storage technology in OODB is that all data received/written to the system are structured using a special software algorithms and stored as unique database objects, that describe (modelled) the energy and power parameters of real-world objects (power plants, transmission lines, power systems etc.). Types of objects in the OODB can be different and independent. DB objects can be regions or countries, national power systems, power plants, electric ties, figure 2 .

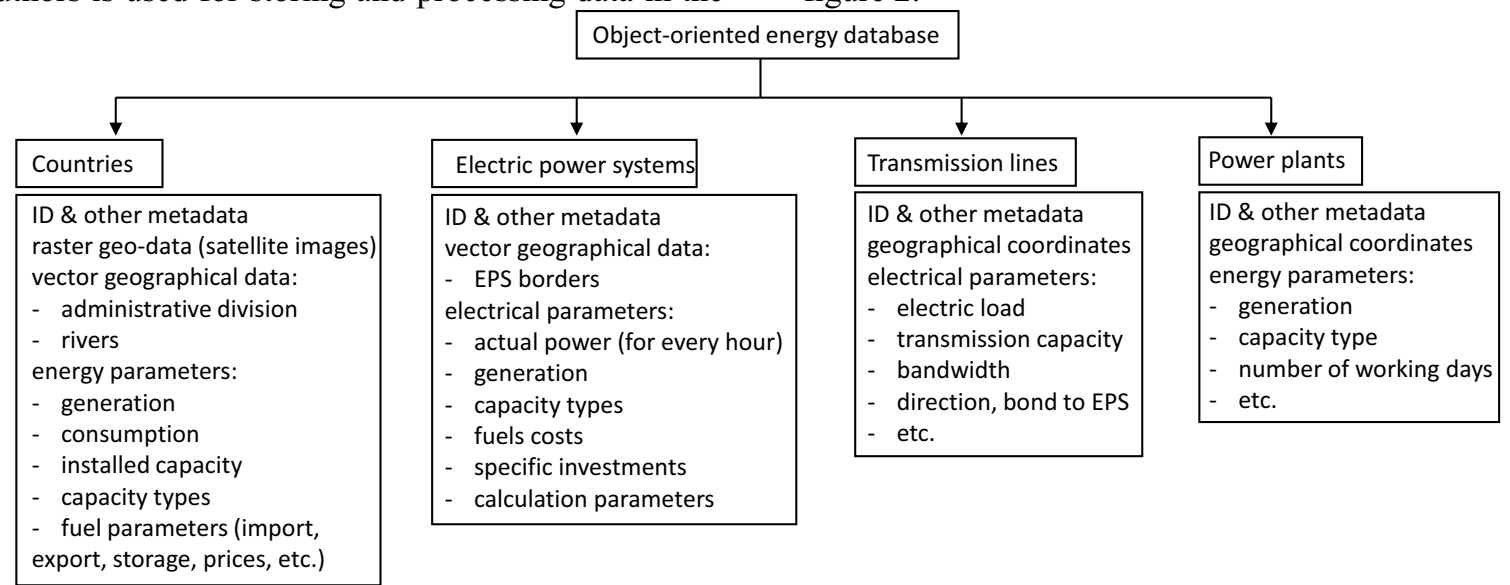

Fig. 2. The CGIS database logical structure.

Each object is a logical record containing a unique object identifier, a set of parameters describing it, and the values of each parameter in text or numeric form, stored by year, month, day, and so on. This type of storage allows one to accurately verify objects collected from various sources and external databases. OODB has a file data structure. The internal structure of files is convenient not only for machine processing, but also understandable to human. The data structure's flexibility and accessibility makes it almost independent of the software components and processing procedures.

The authors have developed special software algorithms for data input / output and their analysis in the CGIS interfaces.

\section{Computing part of the CGIS}

The computing module of the CGIS is designed to work with the integrated optimization model. A special interface allows experts to configure and to change the parameters and constraints of the model and the configuration of nodes and links of the ISPG scheme, to run the "optimizer" and to generate a final set of tables with the results of the optimal solution.

For the ORIRES model, objects of the "node" type are used - these are national EPSwith their energy parameters from OODB.

In this model, a linear optimization method is used to find a solution, which determines:

- the optimal installed capacity and generation type mix of the considered power systems and their interconnections,

- the intersystem and interstate electric ties transfer capabilities,

- the operating modes of these capacities and ties.

The optimal solution of the model is determined by the minimum of annualized costs for the ISPG as a whole. The model is optimized within certain constraints: on capacity and power balances and other constraints - on installed capacity, on electric ties expansion, etc. A detailed description of the model can be found in the book of Lev S. Belyaev et al. The effectiveness of interstate electric ties (Novosibirsk: Nauka, 2008) [11].

Figure 3 shows a graphical representation of the optimized parameters of one of ISPG nodes. 


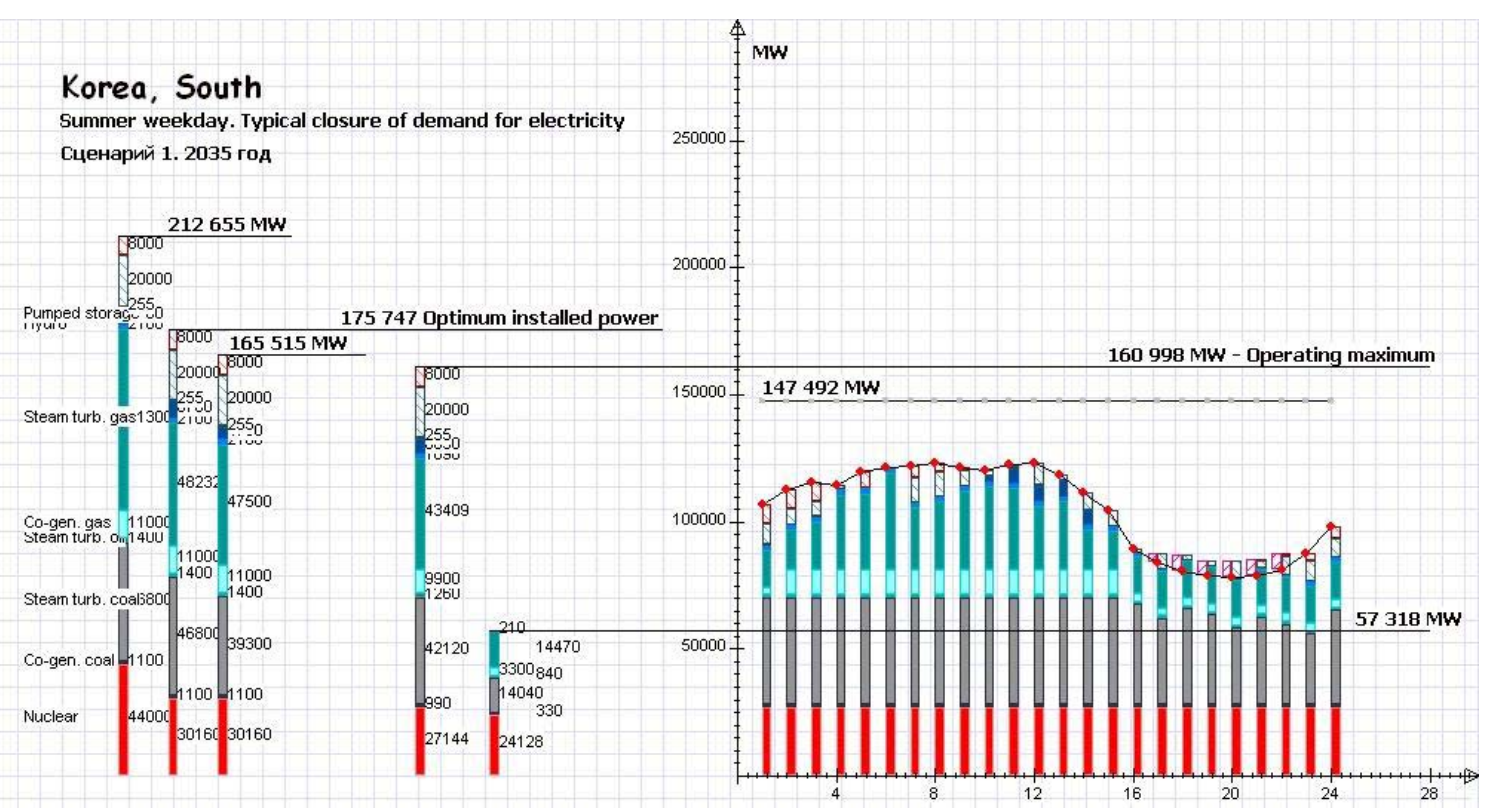

Fig. 3. Graphical representation of South Korean node's parameters and constraints.

Consumers demand is characterized by graph of daily electrical load, which determines how much electricity needs to be generated for each hour (of all 24 hours). The problem of determining the actual power for each type of power plants (co-generation coal fired power plants, gas fired, oil fired, hydro power plants, pumped storage, nuclear, wind, solar and others) is solved, taking into account the electricity transfer between nodes of ISPG diagram.

The main result is a solution, which takes into account the minimum annualized costs, computing the optimal structure of various capacity types (in each node of the ISPG) and their optimal operating modes (at each hour of the day and in different seasons of the year).

All the above parameters and constraints of the model (input data) are configured in forms via the CGIS interface. The interface for entering input parameters and model constraints includes:

- form for setting parameters and constraints of the node,

- form for setting the graph of electric load,

- form for setting the parameters of electric ties between nodes, Figure 4.

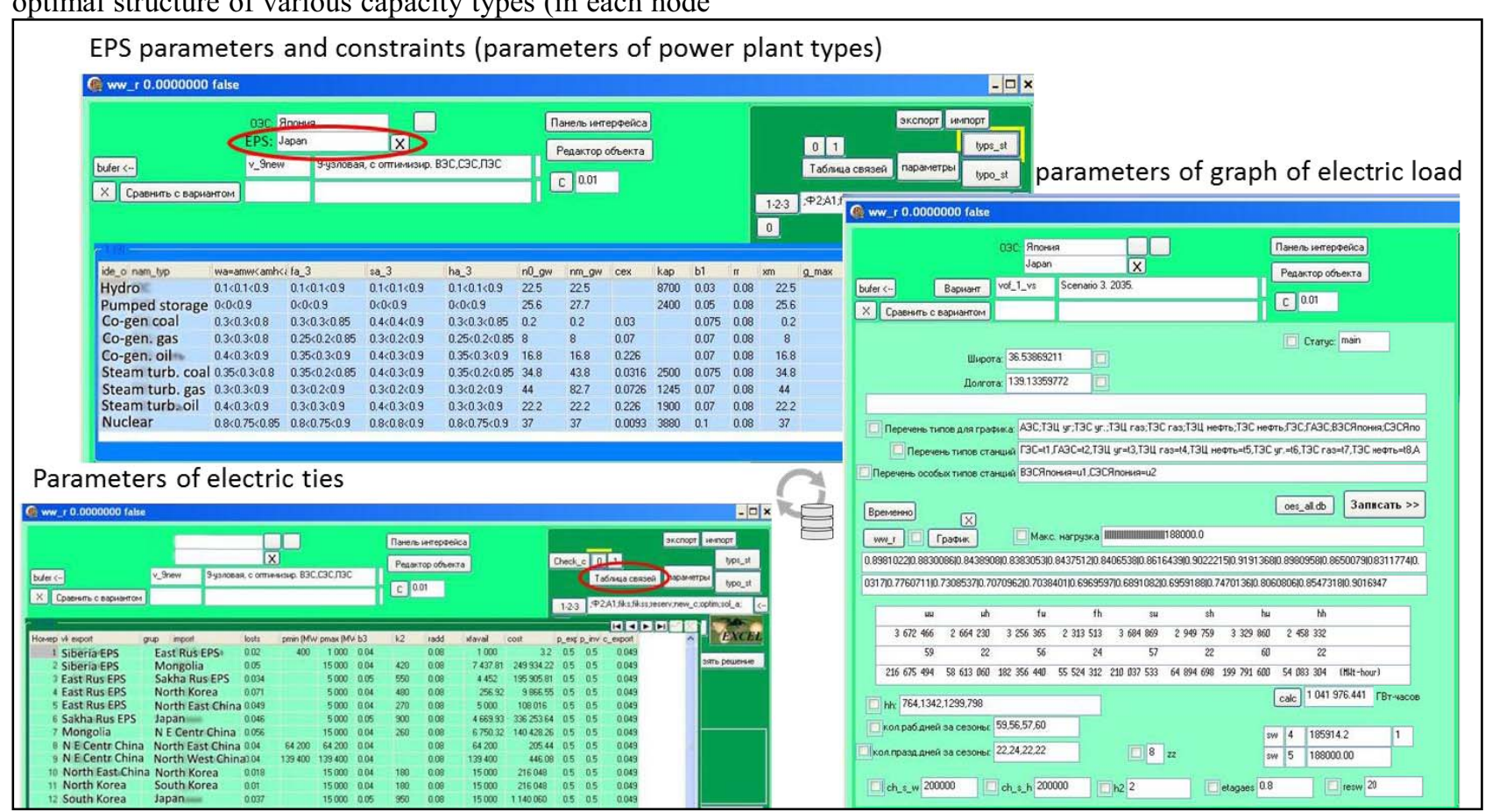

Fig. 4. Forms for input model parameters and constraints in the CGIS interface.

In the software implementation of the ORIRES model, all its equations and parameters are written in a special language of the algebraic modelling system GAMS (also it can be any other optimizer), which is 
launched from the CGIS, reads the model parameters set in the CGIS interface, and creates the optimal solution. The output spreadsheets are presented in tabular form with a very large dimension. Therefore, further work consists in aggregating the output spreadsheets for their subsequent analysis and representation.

\section{Cartographic module of the CGIS (geoinformation mapping)}

The results obtained by the model also can be presented in the cartographic module of the CGIS.

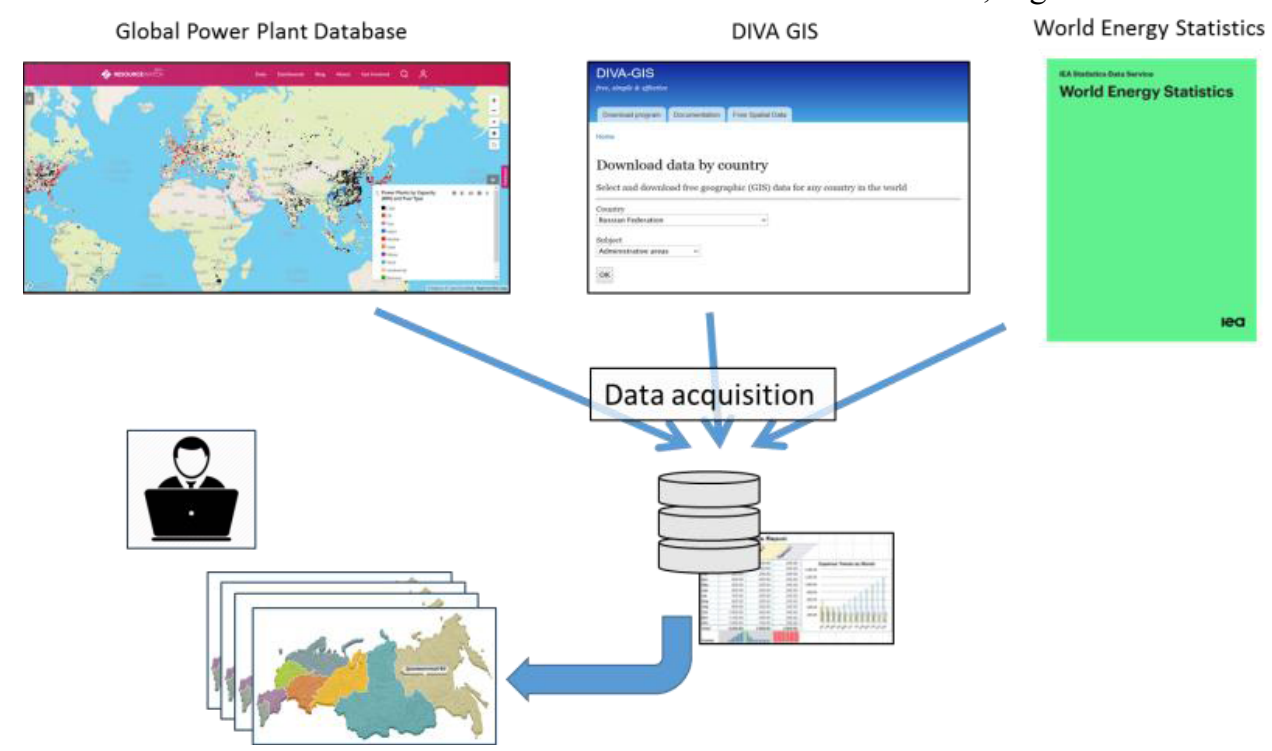
data: analysis of the map of selected territory, not only for the Northeast Asia (NEA), on the model. from various sources, Figure 5.

The cartographic module uses three different types of

1) raster data used as a background layers for

2) vector data - borders of all administrative regions; the CGIS can be used to study of ISPGs in any regions,

3) graphical layers for visual analysis, containing certain energy information from the database about the modelled objects, as well as obtained during calculations

The database of the CGIS contains data collected

DIVA GIS

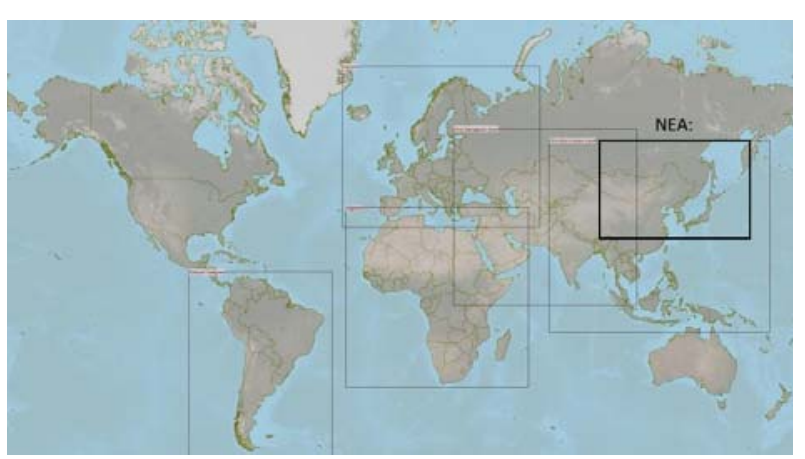

Fig. 6. Atlas geoinformation mapping in the CGIS cartographic module.

At the required scale, the user can combine vector layers with the borders of administrative regions or national power systems, with raster layers of the selected territory. The CGIS allows one to display the geographical coordinates of power plants from the database on the map of selected region, and aggregate their parameters by provinces, power systems, or countries.

To analyze the results of solving the model in the cartographic module, the user can build on the map a scheme of ISPG with the certain parameters and connections between the nodes (interstate electric ties). Figure 7 shows the hybrid map with the 10-node scheme 


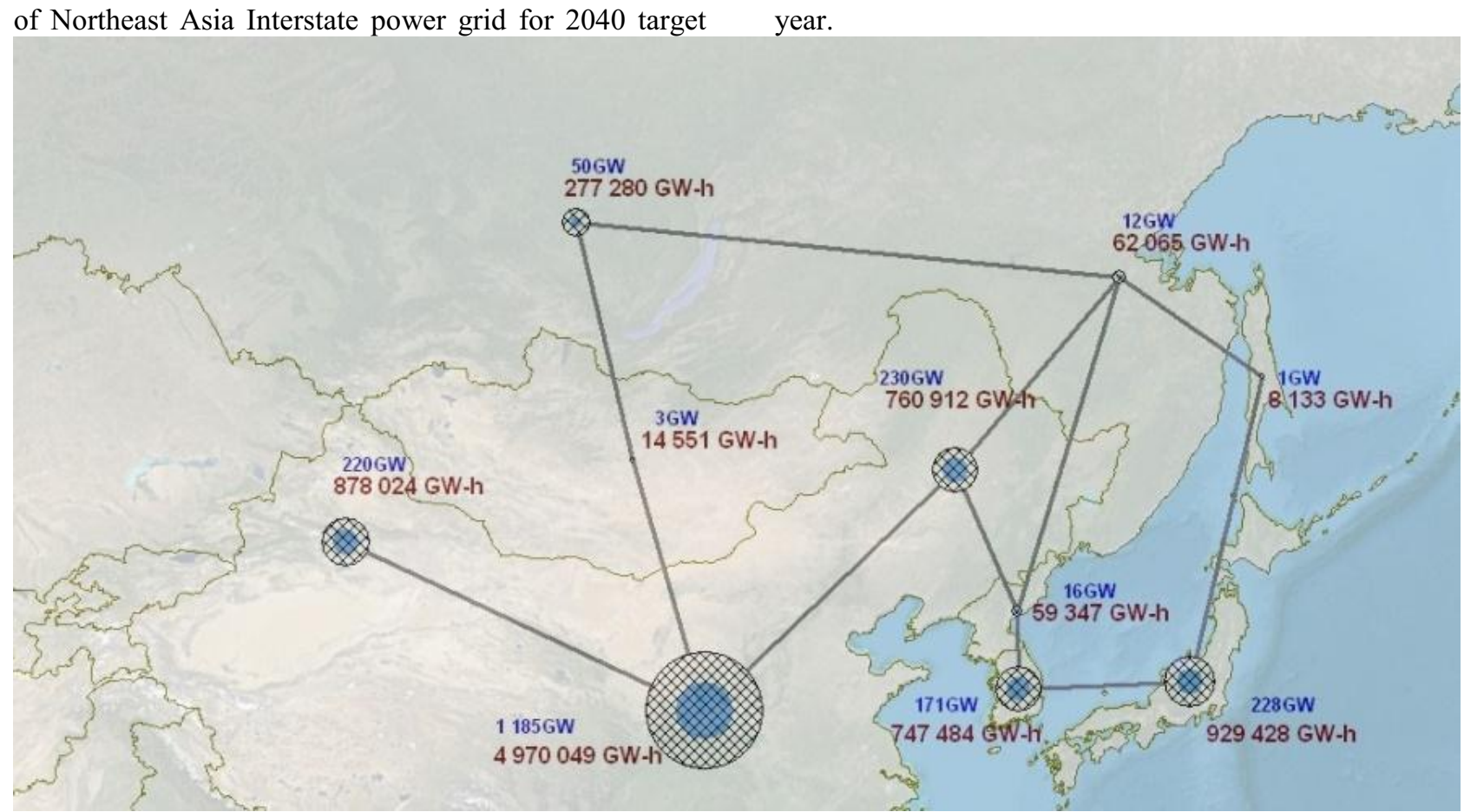

Fig. 7. Hybrid map. The 10-node scheme of NEA ISPG for 2040.

\section{Conclusions}

The new software tool (the CGIS) developed by the authors allows one to carry out a comprehensive analysis of prospective interstate electric ties and power grids of the selected regions. With the CGIS, some new opportunities have appeared for presenting the results of optimization by the ORIRES model (reflecting the operation of power systems in various configurations / scenarios, in tabular and graphical forms).

Now it is possible to flexibly adjust (edit) the initial parameters of the model, the new ability to modernize the model (edit equations and model constraints, add new variables, etc.). This year the authors have carried out the study of optimization of renewable energy capacities at the Northeast Asia interstate power grid.

The new software tool developed by the authors for the study of prospective interstate power grids expansion improves the quality and efficiency of scientific research in this area.

The research was carried out under State Assignment Program No. III. 17.6.2 (AAAA-A17117030310447-3) of the Fundamental Research of Siberian Branch of the Russian Academy of Sciences and partly supported by the Russian Foundation of Basic Research, Grant No. 18-07-00495-A.

\section{References}

1. A. Tofael, S. Mekhilef, R. Shah, N. Mithulananthan, M. Seyedmahmoudian and B. Horan, "ASEAN power grid: A secure transmission infrastructure for clean and sustainable energy for South-East Asia," Renewable and Sustainable Energy Reviews, 67, 2017
2. L. Xuming, "Application and research of global grid database design based on geographic information," Academic Journal of the Global Energy Interconnection Development and Cooperation Organization, 1, 1 (2018)

3. J. Yoon, D. Park and H.Y. Kim, "The Prefeasibility Results of NEAREST between the ROK, and the DRPK, and RF", in Proc. 6th Intern. conf. Asian Energy Cooperation: Forecast and Realities, Irkutsk, 1 (2008).

4. L.S. Belyaev, L.Yu. Chudinova, O.V. Khamisov, G. Kovalev, L. Lebedeva, S.V. Podkovalnikov and V.A. Savelev, Studies of interstate electric ties in Northeast Asia, International Journal of Global Energy Issues, 17, 3 (2002)

5. S.V. Podkovalnikov, V.A. Savelev, O.V. Khamisov, L.Yu. Chudinova, "Justification of Effectiveness of International Power Interconnections with Separation of Effects between Participants," Automation and remote control, 10 (2018).

6. L.Yu. Chudinova, S.V. Podkovalnikov and I.L. Trofimov, Multilateral cooperation for power interconnection in Northeast Asia // 10th International Conference on Asian Energy Cooperation «AEC 2017». E3S Web Conf., 27, 1 (2018)

7. S.V. Podkovalnikov, I.L. Trofimov, L.N. Trofimov, L.Yu. Chudinova, L.S. Belyaev, V.A. Savelev Computing and Information System for Research of Prospective Electric Power Grids Expansion // Yugoslav Journal of Operations Research, [S.1.], 29, 4 (2019)

8. I.L. Trofimov, L.N. Trofimov, S.V. Podkovalnikov, L.Yu. Chudinova. Output Forms for Calculation Results in the Computing \& Geo-Information System // VI International workshop "Critical Infra- 
structures: Contingency Management, Intelligent, Agent-based, Cloud Computing and Cyber Security" (IWCI 2019). Advances in Intelligent Systems Research. Atlantis Press, 169 (2019)

9. S.V. Podkovalnikov, I.L. Trofimov and L.N. Trofimov, Data processing and optimization system to study prospective interstate power interconnections // 10th International Conference on Asian Energy Cooperation «AEC 2017». E3S Web Conf., 27, 1 (2018)

10. O. Zolotova, E. Skupinova, D. Bondarenko, V. Drobyshev, "GIS and Atlas mapping," ArcReview Electronic Journal, 1, 44 (2008) [In Russian]

11. L.S. Belyaev, S.V. Podkovalnikov, V.A. Savelyev, L.Yu. Chudinova, The effectiveness of interstate electric ties (Novosibirsk: Nauka, 2008) [in Russian]

12. DIVA GIS. Available: https://www.diva-gis.org/, [Accessed: 13 April 2019]

13. World Resource Institute. Available: https://datasets.wri.org, [Accessed: 10 February 2020]

14. International Energy Agency. Available: https://www.iea.org, [Accessed: 15 March 2020] 